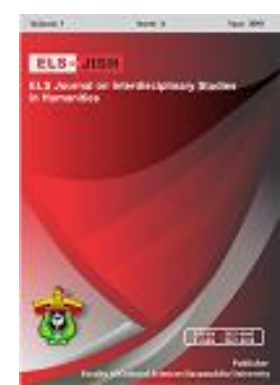

ELS-JISH

ELS Journal on Interdisciplinary Studies on Humanities

Volume 2 Issue 3, 2019

ISSN (print) : 2621-0843

ISSN (online) : 2621-0835

Homepage : http://journal.unhas.ac.id/index.php/jish

\title{
Investigating the Implementation of Critical Literacy Approach in the Middle-East Education Contexts: Three Main Constraints
}

\author{
Sadegh Rahimi Pordanjani ${ }^{1}$, Loade Muhammad Firman Guntur ${ }^{2}$ \\ 1srah0006@student.monash.edu
}

\begin{abstract}
Critical literacy, which is derived from critical pedagogy and critical thinking, is crucial for teachers and students to acquire throughout their education. According to critical literacy approach, students are not only expected to read and write different texts but are also required to challenge, synthesize, analyze, and go beyond these forms of skills analytically and critically. With regard to reviewing various literature, this approach is not implemented effectively in the Middle east education systems due to some main obstacles. This paper is aimed at reviewing different literature and case studies in order to grasp these pivotal constraints that students and teachers encounter while learning and teaching in Middle-Eastern educational settings. The main purpose of this article is to review critically the domination of education by politics and religion, the lack of communicative language teaching approach, and the exclusion of teachers from making decisions as the major impediments of enacting critical literacy in the Middle-east contexts.
\end{abstract}

Keywords: Critical Literacy, Teaching Constraints, Middle-East Education

How to cite: Rahimi, S. P., \& Guntur, L. M. F. (2019). Investigating the Implementation of Critical Literacy Approach in the Middle-East Education Contexts: Three Main Constraints. ELS Journal on Interdisciplinary Studies in Humanities, 2 (3), 410-418

\section{Introduction}

Due to the appearance of globalization and the domination of world by governmental and economic agents throughout the world, socio-political issues such as injustice, imperialism, and inequity have been emerging. Therefore, such negative issues triggered intellectuals such as Freire and Maclaren to provide harmony and justice for nations through critical literacy pedagogy in education (Rashidi \& Mozaffari, 2012). The critical literacy approach is significant in education because this movement emphasises the development of cognitive skills at the center of educational sectors. Critical literacy as postmodern approach is rooted in Freirean critical pedagogy which assists students and educators to analyse and go beyond specific circumstances of socio-political educational issues as well as cultural marginalization. This approach investigates and reflects on the world's problems such as power sources, injustice, and inequity via new lenses in order to transform the globe into a better sphere by subsiding social sufferings (Sluys, Lewison, \& Flint,

\footnotetext{
${ }^{1,2}$ Monash University, Australia 
2006). The concept of critical literacy moved from reading the word to reading the world by focusing on questioning the status quo and analysing the prior knowledge and social order. This approach involves an understanding of how discourses and texts can be constructed, deconstructed, and reconstructed in order to represent, contest, and transform social and semiotic relations (Freire, 1970; Freire \& Macedo, 1987; Luke \& Dooley, 2011, p. 856).

Based on numerous case studies undertaken in the Middle East contexts, policymakers disregard learners and educators from challenging and getting engaged with social issues in classrooms (Qanbari, 2011; Abednia \& Izadinia, 2013; Rahimi \& Askari, 2015; Neophytou \& Valiandes, 2013; Zare-Behtash, Izadi, \& Rezaei, 2017). The aim of this article is to investigate instinct literature in order to identify what challenges critical literacy faces upon its implementation in such contexts. Undoubtedly, critical literacy as an effective pedagogy provides benefits for societies to a great extent. However, it faces three key constraints comprising the domination of education by religion and politics, the exclusion of teachers from making decisions, and the lack of communicative language teaching approach (CLT). At the end, this paper will draw a plausible conclusion before providing useful implications.

\section{Method}

In order to conceptually elaborate the three main constraints on implementing critical literacy for Middle-Eastern contexts, this paper applies conceptual research with critical review to synthesize necessary information. A synthesize research builds on the findings and the discussion from several previous empirical studies in order to generate data. Previous studies surrounding the three emerging themes, which are the political and religious domination in educational sectors, the lack of communicative teaching approach (CLT), and teacher's exclusion in curriculum consideration process are collected. Most reviewed studies in this paper come from Middle-Eastern contexts which, then, provide valuable insights for its endeavour.

\section{Findings and Discussion}

Regarding to the current literature and case studies, the three obstacles such as the domination of education by religion and politics, the lack of communicative language teaching (CLT) approach, and the exclusion of learners and teachers from making decisions will be discussed below critically towards the application of critical literacy in the Middle-East contexts. Such literature is reviewed critically by highlighting distinct researcher's points of views from different Middle-East contexts in order to enhance the validity of arguments.

\subsection{The domination of education by religion and politics}

According to Rahimi and Askari's (2015) study, having arguments beyond governmental and religious issues with the aim of enhancing critically student's literacy disturbs peaceful conditions of classrooms. Thus, teachers are cautious to divert learner's attentions away from such topics. Jayarani and Harland (2014) represent that in such authoritarian systems, where societies are repressive and freedom of speech is curtailed by politics and religion, challenging issues can bring personal risk for educators. Participation of students from religious and military background in Lebanese schools, analysing political and religious issues place 
teachers in dangerous positions and sometimes renders them torture and death. They elaborate that because religious students are supported by the government, they stay silent, show their dissatisfaction, and stand against teachers while analyzing such issues. For example, some students approached teacher and objected her from religious arguments, as a result students threatened teacher and represented their refusal to implement critical literacy in the class.

Abednia and Izadinia (2013) maintain that this political and religious domination cultivates a culture of silence and fear in education. Safari and Rashidi (2016) represent that textbooks and resources are replete with rituals and traditions. If students and educators change these views and norms which is taboo, they will be deprived from going to higher education and having professions. Besides, Ibrahim (2016) expresses that It is difficult for educators who are the product of this educational system to stand outside the system, question the invisible and integral norms, and reform the constructed reality of society. Because some teachers are religious, their beliefs and ideologies contradict critical literacy's principles, so they cannot make students critical in their cognitions.

On the contrary, Ghanbari (2011) states that in Israeli-Arab schools in Palestine even if classes contain students from Christian, Jewish, and Muslim backgrounds, students respect each other and feel free to go beyond the texts. Even though student and teachers' values, beliefs, as well as their religious and political perspectives are different from one another, such outlooks trigger them to look at textbooks deeply and differently and relate socio-political issues to their own personal relationships. She mentions that these ideologies are crucial and helpful for teachers and instructors since they underlie their present attitudes and influence the way they analyze these problems in the texts. For instance, in Palestinian schools, teachers encourage students to respond to the texts, consequently, learners address such issues both in personal and critical ways to speak against injustice in order to promote social justice. Students promote their social justice via some powerful slogans by going on demonstration, representing their voices, re-creating their own identities as activists, and getting some positive reactions towards equality and democracy in the real world.

However, Farhadi and Hedayati' (2009) paper refute Ghanbari's (2011) findings. They report that in Iran there is an interconnection between political rules and religious beliefs, by stating that "our religion is similar to our politics" and "our politics is as the same as our religion". In other words, this statement delivers a message to educators that being opposed to government means being against to Islamic perspectives. Romani (2009) claims that in Palestine and Egypt, the majority of universities and campuses are dominated by powerful political forces. Arab academe engages the interest of government in order to control their educational settings. Romani's report reveals that in Egypt, if students and educators are threats for government and religion, authorities cannot tolerate this condition.

Romani (2009) elaborates that university learners that are dealing with critical approaches such as critical literacy and critical pedagogy in humanities and liberal sciences are sources of insecurity for the governments. As a results, social science students face more restrictions on developing new ideas and are more vulnerable to the lack of pursuing their university majors. While learners in the scientific fields and laboratories can undertake research with minimal limitations. Therefore, critical 
approaches that are related to the humanities and liberal sciences cannot be developed but domesticating these sciences with the framework of their societies.

\subsection{The lack of communicative language teaching (CLT) approach}

Rashidi and Mozaffari (2012) state that education in the Middle-East is examination based system focusing more on grammar translation method (GTM). Educators choose GTM as their instructions because students want to pass exams and go to university so that they can obtain degrees and find professions. Rashidi and Mozaffari (2012) clarify that based on GTM, learners are supposed to focus more on test's skills and commit to their memories some contents without using their critical thinking skills. Hence, learners and teachers are not capable of questioning socio-political issues because they lack knowledge of what critical literacy means or how to apply it correctly.

Sahragard et al. (2014) believe that the higher expectations of parents towards their children to go to university, make teachers to teach examination techniques rather than communicative language skills. They report that teacher's performances are assessed with a weightiest factor which is student's score, if students do not have high grades in passing tests, teachers will be the target of criticism. In this regard educators have no options but prepare students for learning exam techniques. Based on Safari and Pourhashemi's (2012) case study, it is highlighted that when teachers want to give instructions regarding critical literacy, they are faced with student's negative reactions. Learners expect their teachers to follow previous courses' guidelines such as assigning homework as well as teaching test's techniques.

On the other hand, Izadinia and Abednia (2010) mention that due to communicative activities in group discussions, reading materials, listening to classmates, and reflecting opinions in journal writings, students became more critical toward sociopolitical issues. According to their report, all students could demonstrate their critical analyses in interactions as well as reflective essays. In other words, during analyzing different angles of issues in the textbooks, learners were more inspired to cooperate with their peers, give them feedback, and finally reach new solutions for such issues. Izadinia and Abednia' findings conclude that critical literacy classes have sharpened student's communicative language skills as well as their cognitive skills significantly.

On the contrary, Askari (2015) conclude that students are not given an opportunity to express themselves via group discussions and silencing is considered to be an indispensable part of educational system and no one can hear the voices of students and teachers behind the classroom's doors. Qanbari (2011) presents that learners and educators in the Middle-East are living in a collectivist society where they must obey norms, values, and patterns of their societies. It means, they are reluctant to communicate and question the issues such as inequality and inequity in the class because it is against their collectivist tendencies, but more keen on memorizing some grammatical structures and vocabularies. He maintains that learners are obliged to be silent and polite and respect to their teachers in the class by taking notes and listening to instructions rather than speaking.

Abednia (2010) report that in this traditional system of education, the first week of schools, students ask teachers to concentrate more on reading and linguistics 
skills in order to pass exams. Safari and Pourhashemi (2012) argue that instructional textbooks are working toward reading comprehension, grammar, and vocabulary and teachers are expected to translate target language into their mother tongue. These skills are the focus of GTM which shadows the banking model of education in the Middle East contexts. Besides, Allamnakhrah (2013) presents that in Saudi Arabia, the problem starts from the early stages because students and teachers are residing in an uncritical society where critical communications are not encouraged even between parents and their offspring. He elaborates that since the beginning of learner's childhood, parents teach them questioning authorities and teachers is symbol of rudeness and disrespectfulness.

\subsection{The exclusion of learners and teachers from making decisions}

Neophytou and Valiandes (2013) report that educators, who are obliged to accept preplanned lessons and imply top-down guidelines without intervening their own reflections, are out of their critical thinking capacities. They mention that in the Middle-East, where authorities and academics are oppressors, teachers become oppressed and passive recipients like empty vessels waiting to be filled with knowledge of policymakers. They exemplify that in Cyprus, academics from main departments present guidelines. Then, teachers in the training sessions become like students receiving ready-made knowledge and must imply such instructions in their classrooms. Sahragard et al. (2014) support that since materials have been preplanned by authorities, there will be no place for teachers to share their own knowledge and assessment. Therianos (1997) concur that in Cyprus, the rigid system of education does not allow educators to intervene in political and pedagogical issues.

In the Middle-East educational systems, principles do not hear educator's voices and take their needs not into considerations, educational departments dictate some predetermined resources to teachers to apply them correctly (Zare-Behtash, Izadi, \& Rezaei, 2017). It means, if principles do not like lecturer's styles of teaching, they will give them negative points which affect their promotions and positions. Safari and Pourhashemi (2012) report that postmodernism pedagogies like critical thinking, critical pedagogy, and critical literacy cannot be adapted in the Middle-East instructional contexts because such authoritarian structure of education robs teacher's enthusiasm in processing different sorts of topics.

However, Ghanbari (2011) reports that in the class, all the students have discussions about issues such as sex, politics, and religion and teachers choose reading materials which are not pre-determined which their topics are based on students' private lives and experiences. She mentions that students question political and religious issues affectionately which open a new window for their personal relationships and politics of their communications. In other words, students challenge both local and global societal issues and find some logical solutions for them by using their innovations in shifting other classmate's viewpoints. He states that teachers use picture books towards student's religion in their class and learners are willing to start questioning their religious beliefs. By the help of their teachers, their reasoning and cognitive skills regarding understanding of their religious viewpoints has changed dramatically. 
Romani (2009) states that since 1980, due to the introduction of 854 law, it has given Israeli government to control all the Palestinian educational resources as well as university admissions and all the books and reading materials must be approved by the military sectors. In other words, authorities believe that educational sites are places for demonstrations and threats for the government. To throw light, Israeli authorities claim that students become rebellious by their teacher's instructions, as a results they closed down some of Palestinian kindergartens and schools. Rahimi and Askari (2015) report that textbooks and materials ratify by the authorities and academics are not suitable for negotiating inside the classrooms' boundaries because they repress and suffocate learners' skills. It means, such materials include safe topics and are socially and politically neutral and are full of new terms and long sentences that are hard to understand.

Abdullah and Hosseini (2012) mention that through the system of powerpowerlessness among authorities, it keeps students and teachers to be passive recipients, obedient, and powerless rather than knowledge producers. Consequently, students prefer to stay silent during challenging and analyzing socio-political issues. The less powerful students use silence as a weapon to be noncommittal regarding powerful figures. They also mention that being silent in the class is natural even when teachers ask some simple questions. Ibrahim (2016) states that the controlling system of schools which is based on traditional teaching method brainwashes learners to obey and follow authorities' rules, it means students are submissive to this system and eventually they become silent and unhappy, otherwise they will lose their security and self- esteem.

\section{Conclusion and implications}

This essay examined that due to the appearance of socio-political issues such as injustice and inequity, some thinkers such as Freire and Maclaren were motivated to fight against such sufferings through critical literacy in education in order to provide people with a better world. Despite the fact that critical approaches such as critical literacy and critical pedagogy can assist learners and educators to become critical intellectuals by challenging social issues with new lenses, nothing can escape the indispensable key roles of three challenges that critical literacy faces in the MiddleEast education systems. The first challenge comprises the domination of educational systems with religion and politics by focusing more on authoritarian systems of education which lead to cultivate culture of silence and fear. consequently, if teachers and students question such issues, they will be refrained from going to higher education or their personal lives will be at risk. Next, according to the shortage of the communicative language teaching approach, the instructional system is test-oriented which emphasises more on the grammar translation method (GTM). This system expects teachers to assist students to pass exams by focusing on reading, grammar, and vocabulary techniques. Finally, due to accepting and applying pre-determined knowledge and materials which do not include hot and controversial topics, educators and students become passive recipients, oppressed, and submissive to the system.

There are some implications which can assist teachers, students, researchers, and also policymakers to apply critical literacy in the Middle-East contexts effectively. First, Izadinia and Abednia (2010) sate that authorities and policymakers should reevaluate educational styles as well as their mindsets and provide practitioners and 
theorists with democratic discussions so that different voices can be heard. Educators should help prejudiced and biased students to change their belief systems slightly by comparing the real world issues both globally and locally. Moreover, Safari and Rashidi (2016) mention that educators should consider all the possible obstacles of critical literacy meticulously so that they can assess the pros and cons of this approach before its enactment. Second, policymakers, material developers, and textbook designers should include challenging and provocative topics in the textbooks in order to furnish opportunities for learners to "read the word" after "read the world" (Safari \& Rashidi, 2016). Izadinia and Abednia (2010) encourage teachers to feel free to select some authentic materials such as articles from magazines, speeches of notable politicians and religious people, and controversial short stories. In other words, some controversial materials can integrate into students' lives in order to motivate them to analyze issues critically. They also mention that the role of teacher in engaging and directing learner to speak against social controversial issues and creating a liberal education cannot be overlooked.

Safari and Rashidi (2016) sate that activities such as small group conversations not only assist learners to develop their communicative language skills but also establish a peaceful environment for them to voice their viewpoints. Third, both teachers and learners should get familiar with critical literacy's principles and theories as well as communicative language skills through introductory training courses in the initial years of schools in order to develop their interactive and communicative skills for the higher education (Rahimi \& Askari, 2015; Neophytou \& Valiandes, 2013). Karadag (2014) determines that although recent studies have been conducted in primary and secondary schools, more rigorous surveys need to be done in universities and colleges. He maintains that there are numerous investigations conducted regarding the implementation of critical literacy from theory into practice in western and Asian countries, though in the Middle-East contexts, this approach is not regarded significantly.

\section{References}

Abdullah, F. S., \& Hosseini, K. (2012). Discursive enactment of power in Iranian high school EFL classrooms. GEMA Online ${ }^{B}$ Journal of Language Studies, 12(2). Retrieved from: http://ejournals.ukm.my/gema/article/view/646/607

Abednia, A., \& Izadinia, M. (2013). Critical pedagogy in ELT classroom: Exploring contributions of critical literacy to learners' critical consciousness. Language Awareness, 22(4), 338-352. doi: 10.1080/09658416. 2012.733400

Allamnakhrah, A. (2013). Learning critical thinking in Saudi Arabia: Student perceptions of secondary pre-service teacher education programs. Journal of Education and learning, 2(1), 197. doi: 10.5539/ jel. v2n1p197

Elyas, T., \& Badawood, O. (2016). English Language Educational Policy in Saudi Arabia Post 21st Century: Enacted Curriculum, Identity, and Modernisation: A Critical Discourse Analysis Approach. In FIRE: Forum for International Research in Education (Vol. 3, No. 3, p. 3). Retrieved from: https://preserve.lehigh.edu/fire/vol3/iss3/3/ 
Farhady, H., \& Hedayati, H. (2009). Language assessment policy in Iran. Annual review of applied linguistics, 29, 132-141. doi:10.1017/S0267190509090114

Freire, P. (1970). Pedagogy of the oppressed. New York: Herder \& Herder

Freire, P., \& Macedo, D. (1987). Literacy: Reading the word and the world. London: Routledge \& Kegan Paul.

Ghahremani-Ghajar, S. S., \& Mirhosseini, S. A. (2005). English class or speaking about everything class? Dialogue journal writing as a critical EFL literacy practice in an Iranian high school. Language, culture and curriculum, 18(3), 286-299. doi: 10.1080/07908310508668748

Ghanbari, A. (2011). A pathological inquiry into the limits and howness of critical thinking in Shiraz university post graduate classroom discourse. Unpublished master's thesis, Shiraz University, Shiraz, Iran. doi: 10.5923/j.linguistics.20120103.01

Ibrahim, N. K. (2016). Critical literacy: Conflicts, challenges, adaptations and transformation?. Studies in English Language Teaching, 4(3), 330. Retrieved from: http://scholink.org/ojs/index.php/selt/article/ view/616/587

Izadinia, M., \& Abednia, A. (2010). Dynamics of an EFL reading course with a critical literacy orientation. Journal of Language and Literacy Education, 6(2), 51-67. Retrieved from: https://eric.ed.gov/?id=EJ1068173

Jeyaraj, J. J., \& Harland, T. (2014). Transforming teaching and learning in ELT through critical pedagogy: An international study. Journal of transformative education, 12(4), 343-355. doi: 10.1177/1541344614550042

Karadağ, R. (2014). Primary school teacher candidates' views towards critical reading skills and perceptions of their competence. Procedia-Social and Behavioral Sciences, 152, 889-896. doi: 10.1016/j.sbspro.2014.09.339

Neophytou, L., \& Valiandes, S. (2013). Critical literacy needs teachers as transformative leaders. Reflections on teacher training for the introduction of the (new) Modern Greek language curriculum in Cyprus. The Curriculum Journal, 24(3), 412-426. doi: 10.1080/09585176.2012.744331

Rahimi, A., \& Askari Bigdeli, R. (2015). Why does critical literacy hit a snag in the Iranian EFL setting? Colombian Applied Linguistics Journal, 17(1), 53-63. doi: 10.14483/udistrital.jour.calj.2015.1a04

Rashidi, N., \& Mozaffari, F. (2012). Education in hope: on the practice of critical pedagogy in Iranian postgraduate and undergraduate EFL classrooms. The Journal of Linguistic and Intercultural Education, 5, 125-151. Retrieved from: https://search-

proquest.com.ezproxy.lib.monash.edu.au/docview/1497034938/fulltextPDF/5A4 D1CCFE67B40CAPQ/1?accountid=12528

Romani, V. (2009). The politics of higher education in the Middle East: Problems and prospects. Middle East Brief, 36(1), 1-8. Retrieved from: http://www.brandeis.edu/globalbrandeis/documents/MEB36.pdf 12 .pdf 
Safari, P., \& Pourhashemi, M. R. (2012). Toward an empowering pedagogy: Is there room for critical pedagogy in educational system of Iran? Theory and Practice in Language Studies, 2(12), 2548. doi: 10.4304/tpls.2.12.2548-2555

Safari, P., \& Rashidi, N. (2016). Iranian EFL teachers' voices on the pedagogy of word and world. JSSE-Journal of Social Science Education, 14(4), 39-52. doi: 10.2390/jsse-v14-i4-1443

Sahragard, R., Razmjoo, S. A., \& Baharloo, A. (2014). The practicality of critical pedagogy from Iranian EFL instructors' viewpoints: a cross sectional study. The International Journal of Critical Pedagogy, 5(2). Retrieved from http://www.partnershipsjournal.org/index.php/ijcp/article/viewFile/598/662

Van Sluys, K., Lewison, M., \& Flint, A. S. (2006). Researching critical literacy: A critical study of analysis of classroom discourse. Journal of Literacy Research, 38(2), 197-233. Retrieved from: http://www.partnershipsjournal.org/index.php/ijcp/article/view/ 598

Zare-Behtash, E., Izadi, I., \& Rezaei (2017) R. Investigating the Applicability of Critical Pedagogy Principles among Iranian EFL Teachers: From Theory to Practice. Retrieved from: http://www.eltsjournal.org/archive/value5\%20issue3/24-5-3-17.pdf 